\title{
Immunohistochemical localization and mRNA expression of matrix Gla protein and fetuin-A in bone biopsies of hemodialysis patients
}

\author{
Giorgio Coen • Paola Ballanti • Giuliana Silvestrini • \\ Daniela Mantella • Micaela Manni • \\ Salvatore Di Giulio • Stefania Pisanò • \\ Martina Leopizzi • Giuseppe Di Lullo • \\ Ermanno Bonucci
}

Received: 31 October 2008 / Accepted: 21 December 2008 / Published online: 17 January 2009

(C) The Author(s) 2009. This article is published with open access at Springerlink.com

\begin{abstract}
Matrix Gla protein (MGP) and fetuin-A are inhibitors of arterial calcifications. In blood of rats, calcium-phosphate-fetuin-MGP complexes, produced in bone, have been identified. Indeed, an association between bone resorption, release of such complexes, and arterial calcifications has been reported. We have investigated the synthesis and localization of fetuin-A and MGP in bone of hemodialysis patients and the possible contribution of bone cells in arterial calcifications. Bone biopsies from 11 hemodialysis patients were used for histology, in situ hybridization of fetuin-A and MGP messenger RNA (mRNA), immunohistochemistry of fetuin-A, and total, carboxylated, and non-carboxylated MGP proteins. Patients
\end{abstract}

G. Coen $(\bowtie)$

Nephrology and Hypertension Unit, Ospedale Israelitico,

Via Dandolo 75,

00153 Rome, Italy

e-mail: giorgio.coen@gmail.com

P. Ballanti · G. Silvestrini · S. Pisanò · M. Leopizzi · E. Bonucci

Department of Experimental Medicine,

Sapienza University of Rome,

Rome, Italy

D. Mantella $\cdot$ S. Di Giulio

Department of Nephrology, S. Camillo Hospital,

Rome, Italy

\section{Manni}

Department of Nephrology, S. Giovanni-Addolorata Hospital, Rome, Italy

S. Pisanò · G. Di Lullo

Clinical Laboratory Unit, Ospedale Israelitico,

Rome, Italy showed various types of renal osteodystrophy, or normal bone. MGP was synthesized and expressed (total and carboxylated) by osteoblasts, osteocytes, and most osteoclasts, while fetuin-A by osteoblasts and osteocytes. FetuinA and carboxylated MGP proteins were positive in the calcified matrix, while total MGP was negative. Osteoid seams were negative to fetuin-A, lightly positive to carboxylated MGP, and occasionally positive to total MGP. Undercarboxylated MGP was mostly undetectable. In adult humans, fetuin-A is produced also by osteoblasts, and not only by hepatocytes, as previously believed. MGP, essentially carboxylated, is synthesized by osteoblasts and most osteoclasts. Increased bone turnover can be an important contributor to arterial calcifications.

Keywords Vascular calcification - Bone biopsy

Renal osteodystrophy $\cdot$ Matrix Gla protein $\cdot$ Fetuin-A

\section{Introduction}

Vascular calcifications are of frequent occurrence in uremic subjects, and it is assumed that they greatly contribute to the increased cardiovascular mortality both in conservative and hemodialysis (HD) stages of uremia [1,2]. Several risk factors of vascular calcifications have been identified. Age and hemodialysis vintage are among the most important. Also serum calcium, phosphate, CaxP product [3], as well as the rates of hyperparathyroidism [4] and of bone turnover [5] are considered of great importance. In addition, inflammation and malnutrition may play a role, directly and/or through the reduction of fetuin-A, an important 
calcium-phosphate solubilizing agent [6]. It has been shown that fetuin-A-deficient mice develop diffuse extraskeletal calcifications when administered a mineral and vitamin D-rich diet [7]. Cross-sectional analyses of patients with end-stage renal disease have shown that lower fetuin-A concentrations in serum are associated with more extensive vascular and heart valve calcifications, and with increased cardiovascular events and all-cause mortality in longitudinal studies [8]. Fetuin-A is known to be synthesized by the liver of adult humans, and it is found in high concentrations in serum and bone.

Another important protein capable of controlling extraskeletal calcifications in experimental animal models is the matrix Gla protein (MGP). MGP-deficient mice die in the first weeks of life due to extensive calcifications of the vascular tree, with consequent rigidity and rupture of the aorta [9]. MGP is a protein mainly found in bone, dentine, and cartilage, which contains five vitamin-K-dependent $\gamma$ carboxyglutamic acid (Gla) residues that confer it a high affinity for calcium and phosphate ions, and for hydroxyapatite crystals. The presence of Gla residues, therefore, is regarded as critical for the function of MGP, while undercarboxylated MGP, which may result from poor vitamin K status, is considered inactive $[10,11]$. Therefore, fetuin-A and MGP can inhibit extraosseous and specifically arterial calcifications, as well as bone mineralization $[2,12]$.

However, the origin of these proteins is not entirely known. There are reasons to believe that the bone cells may give a contribution to the production of these substances. Biochemical studies have demonstrated that, in the serum of rats, fetuin and MGP form a complex with calcium and phosphate which maintains in solution these minerals, otherwise considered in a state of supersaturation, thus able to mineralize extraskeletal tissues [13]. This complex, very probably identical with the calciprotein particles detected by using electron microscopy and dynamic light scattering [14], is convincingly produced in the bone-remodeling compartment (BRC) [13]. In rats, however, the administration of bisphosphonates, inhibitors of osteoclast resorption, was found to prevent the arterial calcifications induced by warfarin or warfarin plus vitamin $\mathrm{D}$, by reducing the release of the calcium-phosphate-fetuin-MGP complex from the BRC [10]. Further experimental studies have shown a direct association between increase of bone resorption, release of the calcium-phosphate-fetuin-MGP complex, and arterial calcifications [12]. Thus, the fetuin-A and MGP inhibition of extraosseous and, specifically, arterial calcifications is probably exerted locally in the soft tissues and can be somehow impaired in cases of high bone turnover and consequent increase of the mineral-containing complexes in the blood $[2,12]$.

The present study was carried out to evaluate the synthesis and localization of fetuin-A and MGP directly in bone tissue of uremic HD patients with a wide range of bone turnover by immunohistochemistry (IHC) and in situ hybridization (ISH). The total, carboxylated, and noncarboxylated forms of MGP were examined. The possible mechanism of how bone tissue, and specifically osteoclast resorption, could be implicated in the calcium-phosphatefetuin-MGP complex formation is discussed.

\section{Materials and methods}

A total of 11 patients (seven men and four women; $49.45 \pm 12.26$ years) with chronic renal failure in HD treatment were considered. Each patient underwent transiliac bone biopsy with a Bordier trocar following a double cycle of per os administration of tetracycline with 12 days interval. The biopsies were taken 4 to 5 days after the last dose administration. Biopsies were fixed in $4 \%$ paraformaldehyde in $0.1 \mathrm{M}$ phosphate buffer at $\mathrm{pH}$ 7.2. They were then cut longitudinally into two halves with a razor blade and washed in buffer solution.

One half was dehydrated in acetone and processed for glycolmethacrylate embedding without decalcification. Sections, 1-2 $\mu \mathrm{m}$ thick, were stained with methylene blue-azure II for histology. Sections, about $5 \mu \mathrm{m}$ thick, were prepared unstained for the analysis of tetracycline fluorescent labels under UV light. Other sections, about 3-4 $\mu \mathrm{m}$ thick, were stained with the aluminon method. Renal osteodystrophy was diagnosed on the basis of morphologic criteria $[15,16]$. Moreover, histomorphometric descriptors were obtained in correspondence of the trabecular bone, by using an interactive color video-based image analysis system [15], and expressed in agreement with the American Society for Bone and Mineral Research [17]. The variable bone formation rate $\left(\mathrm{BFR} / \mathrm{BS}, \mu \mathrm{m}^{3} / \mu \mathrm{m}^{2} /\right.$ day; the volumetric amount of new mineralized bone per unit of trabecular bone surface per day) was considered for the evaluation of bone turnover [18]; mineralization was examined by osteoid volume (OV/BV, \%; percent of trabecular bone volume consisting of osteoid), osteoid thickness (O.Th, $\mu \mathrm{m}$; thickness of osteoid seams), and mineralization lagtime (Mlt, days; the mean time interval between deposition of osteoid matrix and its mineralization) results [19]; the volume of trabecular bone was given by the measure of bone volume (BV/TV, \%; percent of whole trabecular bone volume occupied by calcified and uncalcified bone tissue). Then, the recently proposed turnover/ mineralization/volume (TMV) classification system [16] was applied by considering the standard deviation scores (SDS) of the measured variables [20] in relation to our normal control values [15]. 


\section{IHC and ISH}

The other half of bone biopsy was decalcified in $10 \%$ disodium EDTA in $0.1 \mathrm{M}$ phosphate buffer at $\mathrm{pH} 7.0$ and processed for paraffin embedding. Serial sections (about 2 to $5 \mu \mathrm{m}$ thick) were deparaffinized and treated for $10 \mathrm{~min}$ with $3 \% \mathrm{H}_{2} \mathrm{O}_{2}$ in methanol.

Slides for IHC were washed for $20 \mathrm{~min}$ in phosphatebuffered saline (PBS) containing $0.1 \%$ Tween 20. For MGP detection, sections were incubated for $10 \mathrm{~min}$ in the blocking reagent of the Vectastain Universal Quick kit (Vector Laboratories, Inc; Burlingame, CA, USA). Serial sections were stained with monoclonal antibodies against total (amino acids 3-15; Biodesign International ${ }^{\circledR}$, Saco, ME, USA; dilution 1:200), fully carboxylated (amino acids 35-54; ALEXIS ${ }^{\circledR}$ Biochemicals, Lausen, Switzerland; dilution 1:800), and non-carboxylated (amino acids 3549; ALEXIS ${ }^{\circledR}$ Biochemicals, Lausen, Switzerland; dilution 1:250) MGP by overnight incubation at $4^{\circ} \mathrm{C}$. Immunodetection with secondary biotinylated antibody and the streptavidin-peroxidase conjugate complex was performed by the Vectastain Universal Quick kit. The Liquid DAB+ Substrate Chromogen System (DakoCytomation, Inc.; Carpinteria, CA, USA) was then applied, followed by a counterstain with 1:15 diluted Mayer's hemalum solution.

For fetuin-A IHC, sections were treated with the Superblock reagent (Scytek Laboratories, Inc; Logan, UT, USA). Then, the goat anti-human fetuin-A/AHSG polyclonal antibody (R\&D Systems, Inc; Minneapolis, MN, USA) was applied (1:500 dilution) for $1 \mathrm{~h}$. Immunodetection was performed using the LSAB2 System-HRP kit (DakoCytomation, Inc., Carpinteria, CA, USA). The substrate-chromagen diaminobenzidine and counterstain with Mayer's hemalum were utilized, as already described for MGP IHC.

Negative controls were obtained by omitting the primary antibodies. Positive controls for MGP and fetuin-A were tested by using samples of arteries with atherosclerotic disease. Moreover, samples of fetal liver were tested for fetuin-A. For each antibody, the optimal working dilution was chosen after testing different concentrations.

For ISH, dewaxed sections were permeabilized for $15 \mathrm{~min}$ at $37^{\circ} \mathrm{C}$ with $75 \mu \mathrm{g} / \mathrm{ml}$ proteinase $\mathrm{K}$ (Sigma Chemical Co; St. Louis, MO, USA) and post-fixed in paraformaldehyde $4 \%$ in PBS-DEPC. The double FITC human MGP and the double FITC human fetuin-A HybriProbe ${ }^{\mathrm{TM}}$ kits provided by Biognostick $^{\circledR}$ (Göttingen, Germany) were used in separate slides, respectively. The oligonucleotide sequences of MGP and fetuin-A HybriProbes were based on the NM 000900 and the NM 001622 GenBank Accession number, respectively. The specific probes were hybridized $(1.5 \mu$ l HybriProbes in $25 \mu$ l HybriBuffer-ISH) overnight at $35^{\circ} \mathrm{C}$. After washing in TRIS/ $\mathrm{HCl}$ buffer at $\mathrm{pH} 7.55$ containing $5 \%$ BSA and $0.1 \%$
Tween 20, immunodetection was performed with peroxidase anti-FITC goat antibody (whole molecule) diluted 1:750. Diaminobenzidine (Liquid $\mathrm{DAB}+$ ) was used as chromogen. Sections were counterstained with 1:15 diluted Mayer's hemalum solution. Positive and negative control probes included in the HibriProbe kits were tested. Moreover, negative controls were achieved by omitting incubation with MGP or fetuin-A probes.

\section{Results}

The following diagnoses were assigned: four patients were affected by osteodystrophy with predominant hyperparathyroidism, showing a general increase in bone turnover, increased numbers of osteoclasts within wide Howship's lacunae, and many plump osteoblasts along numerous osteoid seams, together with areas of woven bone and endosteal fibrosis; three patients were affected by osteodystrophy with predominant osteomalacia, characterized by a decrease of bone turnover and a mineralization defect, in which the increased osteoid seams were mostly in contact with flat osteoblasts, while Howship's lacunae with osteoclasts were rarely found: two of these patients had fully developed osteomalacia, being all three osteoid indices (surface extent, volume, and thickness) increased, while one of them showed the so-called atypical osteomalacia, since osteoid seams were increased in surface and volume but not in thickness [19]; one patient was affected by mixed osteodystrophy, which includes signs of both hyperparathyroidism and osteomalacia; one patient had features of adynamic osteodystrophy, characterized by reduced bone turnover, thin osteoid seams almost completely lined by flat osteoblasts, and very few osteoclasts; two patients were free of pathologic bone lesions. The histomorphometric TMV classification of the patients is shown in Table 1 . The aluminum staining was negative in all patients.

\section{MGP}

In all bioptical samples, the IHC for total MGP was negative in correspondence of the calcified bone matrix. Moreover, no staining was found in the osteoid seams, except for one case with advanced hyperparathyroidism and one with severe osteomalacia in which some occasional seams showed a lightly brownish staining. In all cases, some positive osteocytes were found. Immunolabeling consisted of brown aggregates inside the osteocyte cytoplasm. Positive cells were mainly found in correspondence and in proximity to the osteoid seams, or within the calcified matrix next to the quiescent endosteal surfaces. Less frequently, some positive osteocytes were found more 
Table 1 Turnover/mineralization/volume (TMV) classification

\begin{tabular}{|c|c|c|c|c|c|c|c|}
\hline \multirow{2}{*}{$\begin{array}{l}\text { Patient, } \\
\text { sex/age (years) }\end{array}$} & \multirow{2}{*}{$\begin{array}{l}\text { Histopathologic } \\
\text { diagnosis }\end{array}$} & \multirow{2}{*}{$\begin{array}{l}\text { Turnover } \\
\text { Bone formation rate } \\
\left(\mathrm{BFR} / \mathrm{BS}, \mu \mathrm{m}^{3} / \mu \mathrm{m}^{2} / \text { day) }\right.\end{array}$} & \multicolumn{4}{|l|}{ Mineralization } & \multirow{2}{*}{$\begin{array}{l}\text { Volume } \\
\text { Bone volume } \\
\text { (BV/TV, \%) }\end{array}$} \\
\hline & & & $\begin{array}{l}\text { Osteoid } \\
\text { volume } \\
(\mathrm{OV} / \mathrm{BV}, \%)\end{array}$ & $\begin{array}{l}\text { Osteoid } \\
\text { thickness } \\
(\mathrm{O} . \mathrm{Th}, \mu \mathrm{m})\end{array}$ & $\begin{array}{l}\text { Mineralization } \\
\text { lag-time } \\
\text { (Mlt, days) }\end{array}$ & Mineralization & \\
\hline $\mathrm{M} / 32$ & Hyperparathyroidism & High & High & High & Normal & N-abnormal & Normal \\
\hline $\mathrm{M} / 40$ & Hyperparathyroidism & High & High & High & N-high & $\mathrm{N}$-abnormal & N-high \\
\hline $\mathrm{F} / 48$ & Hyperparathyroidism & High & High & High & N-low & $\mathrm{N}$-abnormal & High \\
\hline $\mathrm{F} / 49$ & Hyperparathyroidism & High & High & N-high & Normal & $\mathrm{N}$-abnormal & High \\
\hline $\mathrm{M} / 47$ & Osteomalacia & N/A & High & High & N/A & Abnormal & N/A \\
\hline $\mathrm{F} / 58$ & Osteomalacia & Low & High & High & High & Abnormal & N-high \\
\hline $\mathrm{M} / 39$ & Atypical osteomalacia & Low & High & Normal & High & $\mathrm{N}$-abnormal & Low \\
\hline $\mathrm{M} / 41$ & Mixed osteodystrophy & N-high & High & High & High & Abnormal & High \\
\hline $\mathrm{F} / 71$ & Adynamic osteodystrophy & Low & Normal & N-high & High & $\mathrm{N}$-abnormal & Normal \\
\hline $\mathrm{M} / 50$ & Without pathologic alteration & Normal & Normal & Normal & N-low & Normal & Normal \\
\hline $\mathrm{M} / 69$ & Without pathologic alteration & Normal & Normal & Normal & N-low & Normal & Normal \\
\hline
\end{tabular}

High, >2 SDS from mean; Low, <2 SDS from mean; N-high, 1-2 SDS above mean; N-low, 1-2 SDS below mean $N$-abnormal mildly abnormal, $N / A$ not available

inside the calcified matrix. In adjacent sections, the ISH messenger RNA (mRNA) labeling was mainly localized in the cytoplasm of some osteocytes, with a similar pattern of distribution (Fig. 1).

Apart from the case with adynamic bone disease, in which plump osteoblasts could not be found, these cells resulted positive to the IHC reaction both along the trabeculae and in correspondence of cortical bone, and independently of the type of bone alteration. These same cells were intensely stained by ISH for mRNA (Fig. 1).

Cells of endosteal fibrosis, which could be detected in the bone biopsies of patients with high turnover bone disease (hyperparathyroidism and mixed type of renal osteodystrophy), were positive to both IHC and ISH reactions (Fig. 1).

Multinucleated osteoclasts could not be detected in one case with severe osteomalacia. In all the other cases, most of these cells were variably positive to total MGP IHC in trabecular and cortical bone; however, some negative osteoclasts were found, with no apparent difference in frequency between the types of bone alterations. In agreement with these findings, osteoclasts showed either variably diffused ISH mRNA labeling in the cytoplasm or no signal at all (Fig. 2).

In all samples, the results described above for total MGP IHC coincided with those found by the antibody specifically recognizing the carboxylated form of the protein, in osteocytes, osteoblasts, osteoclasts, and cells of endosteal fibrosis (Fig. 3). For both types of IHC reaction, cell positivity was clearly visible although the antibody concentrations for total MGP and for carboxylated MGP were 5 and 3.2 times lower than those suggested in the respective product data sheet. In contrast to total MGP, in all cases, a

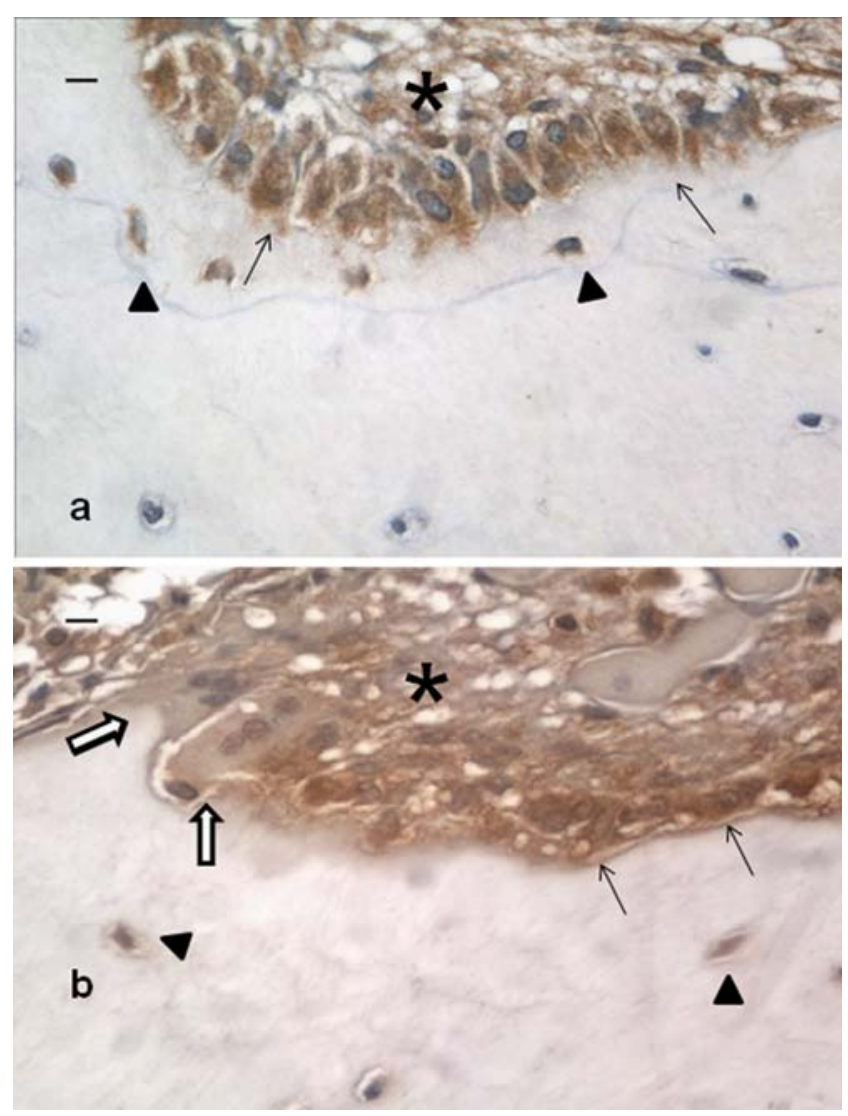

Fig. 1 Total MGP: a osteoblasts (arrows), endosteal fibrosis cells (asterisk), and some young osteocytes (arrowheads) are positive to IHC; b osteoblasts (arrows), endosteal fibrosis cells (asterisk), and some osteocytes (arrowheads) are positive to ISH, while two osteoclasts (empty arrows) are negative. Trabecular bone, hyperparathyroidism. Bars $=10 \mu \mathrm{m}$ 


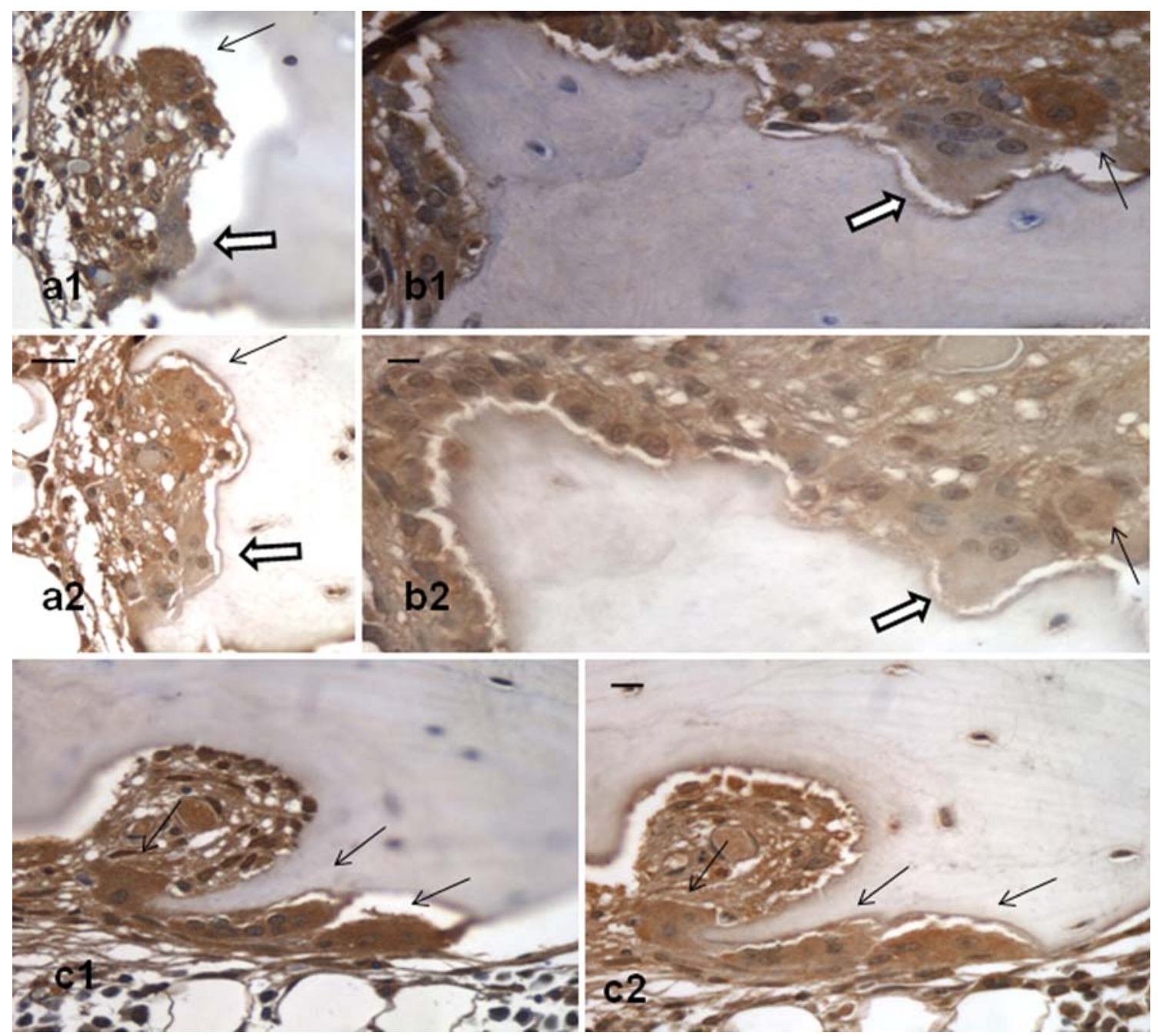

Fig. 2 Total MGP: $(a 1, b 1$, and $c 1)$ negative (empty arrows) and/or positive (arrows) osteoclasts to IHC are visible; (a2, b2, and $c 2$ ) sections adjacent to $a 1, b 1$, and $c l$, respectively: the same osteoclasts

light and diffuse carboxylated MGP immunostaining was found in the calcified bone matrix and in most osteoid seams, although the staining intensity in the latter was very faint (Fig. 3).

In some cases, independent of the type of bone condition, some of the flat, lining cells which border the quiescent bone surfaces were positive to the IHC reaction for total and carboxylated MGP, as well as to the ISH reaction for MGP mRNA. However, because their cytoplasm is characteristically reduced to a very thin rim, the recognition of the labeling of these cells was generally difficult.

Undercarboxylated MGP IHC, performed by using exactly the antibody concentration indicated by the product data sheet, was practically negative in all bioptical samples. Only a very weak immunostaining was present in the osteoid and/or calcified bone matrix of a minority of patients, without any reference to the types of bone lesions. positive to IHC in $a 1, b 1$, and $c 1$ are also positive to ISH (arrow). Trabecular bone, hyperparathyroidism. Bars $=10 \mu \mathrm{m}$

In these cases, rare osteocytes, osteoblasts, and/or osteoclasts were very lightly stained.

\section{Fetuin-A}

The antibody dilution used for fetuin-A IHC was optimized at a concentration which was 10 times lower than the lower limit of the working dilution suggested by the data sheet. In both cortical and trabecular bone of all cases, the IHC reaction was strongly positive in correspondence of the calcified bone matrix. In contrast, the osteoid seams were not stained. Some positive osteocytes were found in all cases within the calcified bone matrix. Sometimes, positive osteocytes were also present in correspondence of the osteoid seams, mainly next to plump osteoblasts (Fig. 4). In agreement with these findings, ISH showed a positive signal within some osteocytes localized in both the calcified matrix and in the osteoid (Fig. 5). 


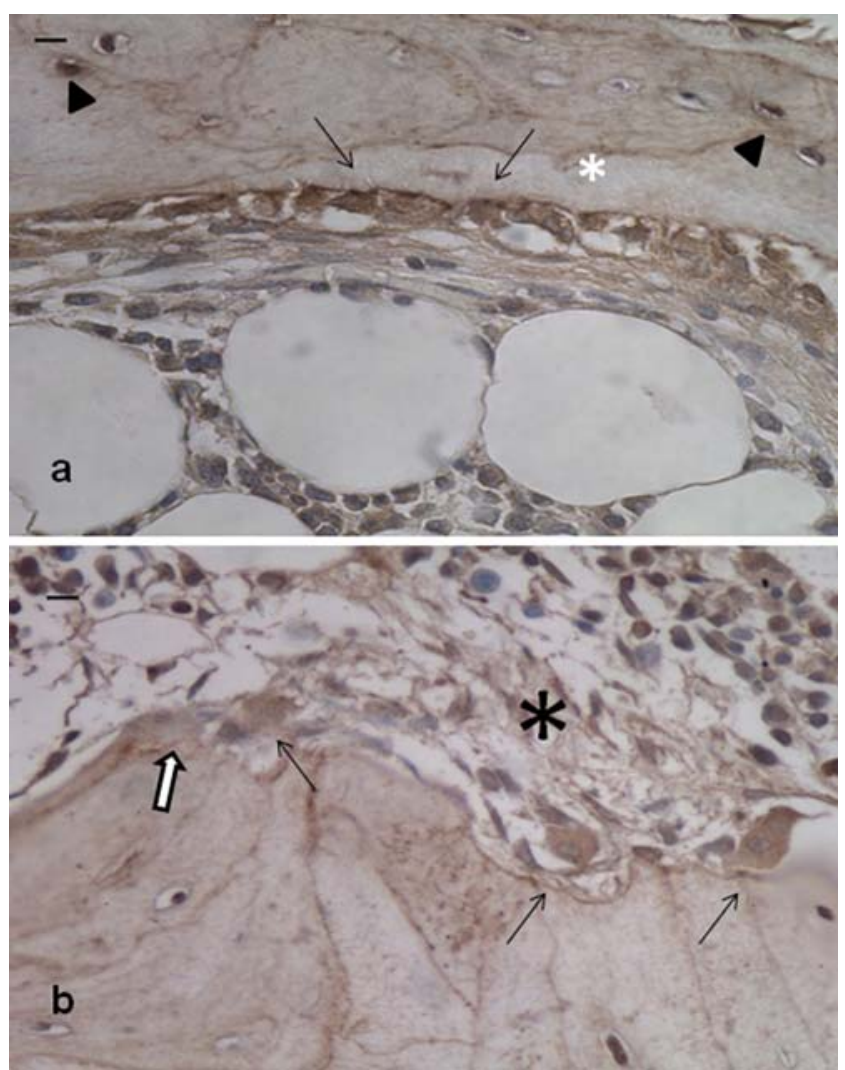

Fig. 3 Carboxylated MGP, IHC: a osteoblasts (arrows) and some osteocytes (arrowheads) are positive, the osteoid seam is barely stained (white asterisk); b one almost negative (empty arrow) and three positive (arrows) osteoclasts, together with positive endosteal fibrosis cells (asterisk) within the Howship's lacuna, are visible. In both $\mathbf{a}$ and $\mathbf{b}$, a diffuse positivity of calcified bone matrix is present. Trabecular bone, hyperparathyroidism. Bars $=10 \mu \mathrm{m}$

In all samples, with the only exception of the case with adynamic osteodystrophy in which active osteoblasts were not found, most of the plump osteoblasts were lightly or intensely stained by the fetuin-A IHC reaction (Fig. 4). Such IHC positivity was confirmed by ISH reactivity (Fig. 5). No differences were found between trabecular and cortical bone.

In bone samples characterized by increased turnover, cells of endosteal fibrosis were positive to both IHC and ISH reactions. Osteoclasts, in all cases in which these cells were found, were negative to both IHC and ISH (Figs. 4 and 5).

In a few cases, some endosteal lining cells appeared immunohistochemically positive and showed a ISH signal. However, as described for MGP, the reaction products of both IHC and ISH in these cells were sometimes hard to be detected due to their very thin cytoplasm.

\section{Discussion}

All patients but two were affected by the wide spectrum of bone cells and matrix alterations, ranging from high to low bone turnover diseases, which are proper of renal osteodystrophy [18].

For MGP IHC, antibodies against total, fully carboxylated, and non-carboxylated proteins were tested, to evaluate the carboxylation status of MGP. For each of the three forms of MGP, the amino acid sequences recognized by the respective monoclonal antibodies corresponded exactly to those of a recent study performed in human arteries [11]. In the vascular wall, the inhibition of $\gamma$-carboxylation of Glu residues yielded the undercarboxylation of MGP and the subsequent calcification of the tunica media [10]. Moreover, it has been shown in the bone tissue of transgenic mice, which produced two distinct mutated forms of MGP in osteoblasts, that the Gla residues are required for MGP antimineralization function [21].

In all patients, the calcified bone matrix was almost completely negative to the antibody directed against the total MGP. This result is similar to that obtained by Spronk et al. [22] in human fetal bone, by using two monoclonal antibodies, against the $\mathrm{N}$ - and C-terminus of MGP. In contrast, Carlson et al. [23] reported slight positive IHC staining for total MGP in widely scattered areas of calcified matrix in vertebrae of monkeys. Such variation in immuno-

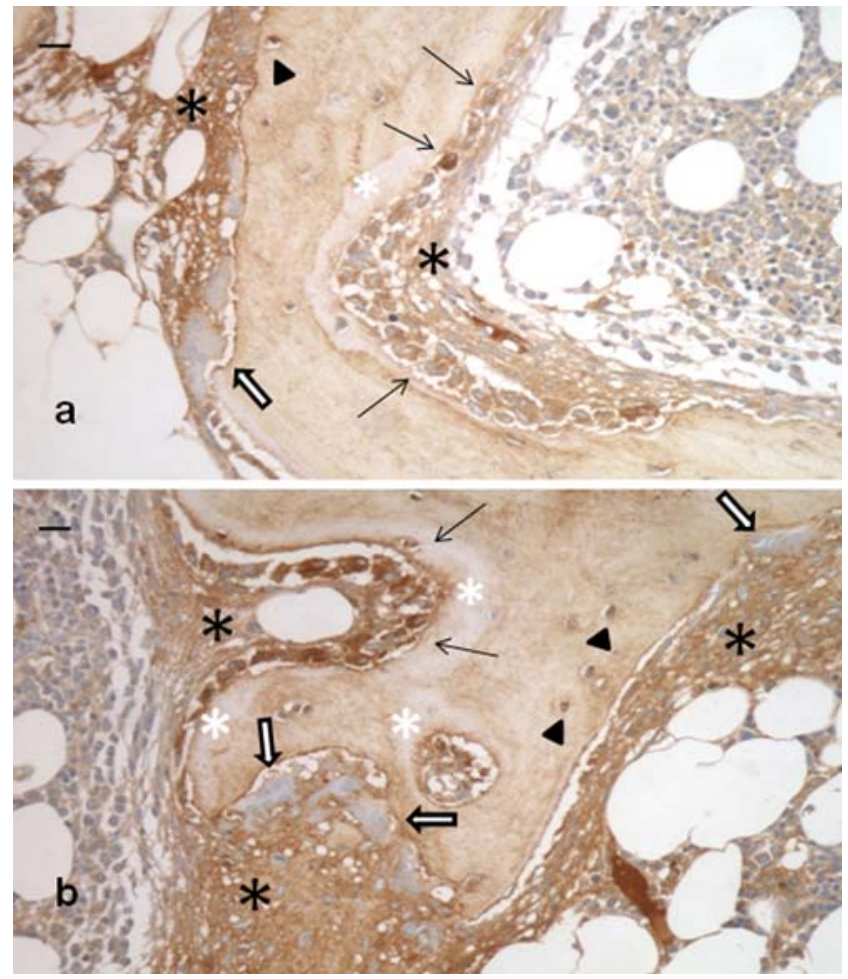

Fig. 4 Fetuin-A, IHC: a osteoblasts with variable intensity of positivity are present (arrows); b osteoblasts are highly positive (arrows). In both $\mathbf{a}$ and $\mathbf{b}$, endosteal fibrosis cells (asterisks) and some osteocytes (arrowheads) are positive, while osteoclasts are negative (empty arrows); a clear positivity of calcified bone matrix is visible, while the osteoid seams are negative (white asterisks). Trabecular bone, hyperparathyroidism. Bars $=20 \mu \mathrm{m}$ 


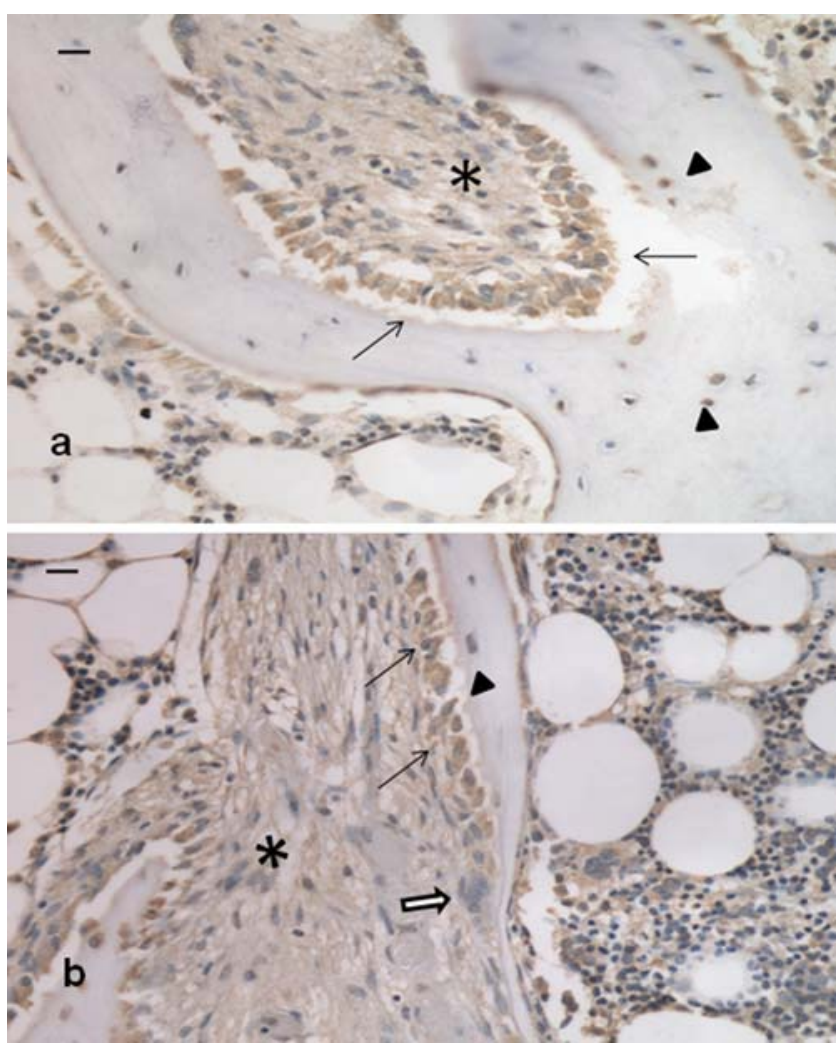

Fig. 5 Fetuin-A, ISH: a, b Osteoblasts (arrows) and some osteocytes (arrowheads) and endosteal fibrosis cells (asterisks) are positive. In b, a negative osteoclast is present (empty arrow). Trabecular bone, hyperparathyroidism. Bars $=20 \mu \mathrm{m}$

reactivity might be due to the different animal species or, most probably, to differences in the sequences recognized by the various monoclonal antibodies. In any case, the calcified matrix in all bone biopsies of the present study was lightly and diffusely immunostained for carboxylated MGP.

Among bioptical samples, only some occasional osteoid seams were immunostained for total MGP in one case with hyperparathyroidism and one with osteomalacia. In human fetal bone, Spronk et al. [22] reported a weak total MGP signal that was associated with the extracellular matrix at sites of non-calcified bone. Moreover, Carlson et al. [23] found some areas of osteoid seams positive to total MGP. These authors suggested that the presence of MGP within the osteoid tissue might have a role in preventing its premature mineralization. In the present study, in contrast to total MGP, a very faint positivity to carboxylated MGP was found in most osteoid seams in all types of bone conditions.

In all bone biopsies, osteoblasts were invariably positive to total MGP. Some IHC positive osteoblasts were also found by Carlson et al. [23]. In our samples, these cells were also positive to the carboxylated form of MGP. Moreover, they expressed the MGP gene. This result appears especially significant on the basis of the contradictory reports available in the literature. Using ISH, Hirakawa et al. [24] could not detect MGP mRNA in rat osteoblasts, although the authors were aware that it had been detected in osteoblastic cell culture. Luo et al. [25] also did not find MGP mRNA by ISH in mouse osteoblasts; they hypothesized, therefore, that, like fetuin-A, the protein could accumulate in bone through blood circulation. In biopsies of human fracture callus, the signal for MGP mRNA was only found in osteoblasts of the woven bone in non-unions, and not in osteoblasts of the old bone [26].

In our bioptical samples, not only osteoblasts, but also some osteocytes, especially those that appeared to be the youngest, were positive to total MGP IHC. This is in contrast with the results of Carlson et al. [23] who found negative osteocytes. However, in our experience, osteocytes were also positive to the carboxylated form of MGP and expressed MGP mRNA. These results are in line with the osteoblastic origin of the osteocytes. Also the findings that some endosteal lining cells are immunostained for the total and carboxylated MGP protein and express the corresponding mRNA are in agreement with the origin of the lining cells from the osteoblasts. Similarly, the observation that the cells of endosteal fibrosis that accumulate in bone marrow in cases of hyperparathyroidism are positive to both total and carboxylated MGP and express the corresponding mRNA might depend on the fact that these cells are probably osteoblast precursors, secondary to parathormone-stimulated proliferation of bone marrow stromal cells [27].

The present study has shown that most osteoclasts are immunostained for total MGP in any type of bone condition, a result in agreement with the findings of Carlson et al. [23]. In our experience, the same cells are immunostained for the carboxylated MGP, too, and ISH has shown that they express the corresponding mRNA.

Undercarboxylated MGP immunostaining was almost negative in all bioptical samples, although some very light positivity was found in a minority of cases in calcified or uncalcified bone matrix and in bone cells. This indicates that the MGP protein present in bone, where calcification is a physiological event, is predominantly in its active form, and demonstrates that, at least locally, there is not a significant vitamin $\mathrm{K}$ deficiency. Interestingly, in the intima of atherosclerotic arteries and in Mönckeberg's sclerosis of the media, where pathological calcifications of different etiologies occur, undercarboxylated MGP was almost exclusively localized in sites of calcification, while total and carboxylated MGP were mostly found in the noncalcified areas of the tunica media [11].

The IHC localization of fetuin-A in the mineralized areas of bone matrix has been already described in normal adult humans [28] and other mammals [29, 30]. Our results show that the protein is highly represented in mineralized matrix of normal bone of uremic patients, as well as in any form of renal osteodystrophy, independent of the rate of bone 
turnover and of the type (lamellar or woven) of bone structure. Osteoid seams were invariably negative: in this respect, no comparative data could be found in the literature.

It is a general opinion, ensued from old findings [28, 31] and confirmed by relatively recent studies [32, 33], that fetuin-A is synthesized in the liver and is incorporated, via the bloodstream, into the bone matrix during the mineralization process, as a result of its high affinity for hydroxyapatite $[2,12,34,35]$. In the present study, most osteoblasts were immunostained for fetuin-A in all types of renal osteodystrophy, as well as in normal bone. Our IHC and ISH findings demonstrate that human osteoblasts do have fetuin-A in the cytoplasm and synthesize it. To our knowledge, these results were not previously described in humans, although some IHC positivity of the rat counterpart of human fetuin-A had been found in osteoblasts of adult rats [29]. Moreover, in a very recent paper, some fetuin-A uptake by osteoblast-like cells was reported [36].

On the basis of our results, the localization of fetuin-A in the mineralized bone matrix appears to be due to an active osteoblast participation, rather than to a mere accumulation of the protein from the blood. The previously reported osteoblast negative results could be probably explained, at least in part, by hypothesizing that the degree of synthesis of fetuin-A in bone of adult humans could be much lower than that in the liver, as it was found in mouse osteoblastic cells [37] and for the rat counterpart of the protein [38].

With reference to fetuin-A, no previous papers dealing with osteocytes in humans have been found. Our results show that some osteocytes are both IHC and ISH positive. Similarly, the IHC positivity of the rat counterpart of human fetuin-A was described in osteocytes of adult rats [29]. As commented above for MGP, these findings, as well as the positivity to both reactions in some endosteal lining cells and cells of endosteal fibrosis in hyperparathyroidism are in agreement with the osteoblastic relationship of these cells.

In vitro experiments have suggested that fetuin- $A$, and its rat counterpart, might stimulate bone resorption [39, 40]. Moreover, it has been hypothesized that osteoclasts may clear the calciprotein particles by phagocytosis [14], thus mediating the recycling of extracellular calcium and phosphate from basic calcium phosphate. However, in our study, osteoclasts were negative to both fetuin-A IHC and ISH, so that no information could be drawn on fetuin-A involvement in bone resorption.

In conclusion, we have examined, for the first time, the localization and the synthesis of fetuin-A and MGP, directly in the bone tissue of patients with chronic renal failure in HD treatment. In contrast with the general opinion that, in adult humans, the fetuin-A is synthesized in the liver, transported via the bloodstream to bone, and incorporated in the calcified matrix, we have shown that it is produced by osteoblasts, too. It is possible that the bone synthesis of the protein can contribute to the formation within the BRC of the calcium-phosphate-fetuin-MGP complex described in rats by Price et al. [13]. The MGP protein, synthesized by osteoblasts and accumulated in bone, is essentially of carboxylated type, thus in its active form. Also, osteoclasts synthesize MGP, which is contained in these cells in the carboxylated form. This new finding suggests that these cells, other than osteoblasts, can be an important source of the calcium-phosphate-fetuin-MGP complexes. In agreement with the findings in rats [12], these results point to the increased bone turnover and specifically to the osteoclastic resorption as important factors which can promote extraskeletal and arterial calcifications in uremia. However, further studies are necessary to confirm whether the calcium-phosphate-fetuin-MGP complexes, detected under some circumstances in rats, are also present in humans, and particularly in uremic patients with artery and soft tissue calcifications [12].

Conflict of interest statement The authors declare that they have no conflict of interest.

Open Access This article is distributed under the terms of the Creative Commons Attribution Noncommercial License which permits any noncommercial use, distribution, and reproduction in any medium, provided the original author(s) and source are credited.

\section{References}

1. Foley RN, Parfrey PS, Sarnak MJ (1998) Epidemiology of cardiovascular disease in chronic renal disease. J Am Soc Nephrol 9(Suppl 12):S16-S23

2. Moe SM, Reslerova M, Ketteler M et al (2005) Role of calcification inhibitors in the pathogenesis of vascular calcification in chronic kidney disease (CKD). Kidney Int 67:2295-2304

3. Coen G, Manni M, Agnoli A et al (2006) Cardiac calcifications: fetuin-A and other risk factors in hemodialysis patients. ASAIO J 52:150-156

4. Ganesh SK, Stack AG, Levin NW et al (2001) Association of elevated serum $\mathrm{PO}_{4}, \mathrm{Ca} \times \mathrm{PO}_{4}$ product, and parathyroid hormone with cardiac mortality risk in chronic hemodialysis patients. J Am Soc Nephrol 12:2131-2138

5. London GM, Marty C, Marchais SJ et al (2004) Arterial calcifications and bone histomorphometry in end-stage renal disease. J Am Soc Nephrol 15:1943-1951

6. Wang AY, Woo J, Lam CW et al (2005) Associations of serum fetuin-A with malnutrition, inflammation, atherosclerosis and valvular calcification syndrome and outcome in peritoneal dialysis patients. Nephrol Dial Transplant 20:1676-1685

7. Schäfer C, Heiss A, Schwarz A et al (2003) The serum protein $\alpha_{2}$ Heremans-Schmid glycoprotein/fetuin-A is a systemically acting inhibitor of ectopic calcification. J Clin Invest 112:357-366

8. Hermans MM, Brandenburg V, Ketteler M et al (2007) Association of serum fetuin-A levels with mortality in dialysis patients. Kidney Int 72:202-207 
9. Luo G, Ducy P, McKee MD et al (1997) Spontaneous calcification of arteries and cartilage in mice lacking matrix GLA protein. Nature 386:78-81

10. Price PA, Faus SA, Williamson MK (2001) Bisphosphonates alendronate and ibandronate inhibit artery calcification at doses comparable to those that inhibit bone resorption. Arterioscler Thromb Vasc Biol 21:817-824

11. Schurgers LJ, Teunissen KJF, Knapen MHJ et al (2005) Novel conformation-specific antibodies against matrix $\gamma$-carboxyglutamic acid (Gla) protein - undercarboxylated matrix Gla protein as marker for vascular calcification. Arterioscler Thromb Vasc Biol 25:1629-1633

12. Price PA, Williamson MK, Nguyen TM et al (2004) Serum levels of the fetuin-mineral complex correlate with artery calcification in the rat. J Biol Chem 279:1594-1600

13. Price PA, Caputo JM, Williamson MK (2002) Bone origin of the serum complex of calcium, phosphate, fetuin, and matrix Gla protein: biochemical evidence for the cancellous bone-remodeling compartment. J Bone Miner Res 17:1171-1179

14. Heiss A, DuChesne A, Denecke B et al (2003) Structural basis of calcification inhibition by $\alpha_{2}$-HS glycoprotein/fetuin-A. Formation of colloidal calciprotein particles. J Biol Chem 278:13333-13341

15. Coen G, Ballanti P, Bonucci E et al (1998) Bone markers in the diagnosis of low turnover osteodystrophy in haemodialysis patients. Nephrol Dial Transplant 13:2294-2302

16. Moe S, Drüeke T, Cunningham J et al (2006) Definition, evaluation, and classification of renal osteodystrophy: a position statement from Kidney Disease: Improving Global Outcomes (KDIGO). Kidney Int 69:1945-1953

17. Parfitt AM, Drezner MK, Glorieux FH et al (1987) Bone histomorphometry: standardization of nomenclature, symbols, and units. J Bone Miner Res 2:595-610

18. Ballanti P, Coen G, Mazzaferro S et al (2001) Histomorphometric assessment of bone turnover in uraemic patients: comparison between activation frequency and bone formation rate. Histopathology 38:571-583

19. Parfitt AM (2003) Renal bone disease: a new conceptual framework for the interpretation of bone histomorphometry. Curr Opin Nephrol Hypertens 12:387-403

20. Waller S, Shroff R, Freemont AJ et al (2008) Bone histomorphometry in children prior to commencing renal replacement therapy. Pediatr Nephrol 23:1523-1529

21. Murshed M, Schinke T, McKee MD et al (2004) Extracellular matrix mineralization is regulated locally; different roles of two Gla-containing proteins. J Cell Biol 165:625-630

22. Spronk HMH, Soute BAM, Schurgers LJ et al (2001) Matrix Gla protein accumulates at the border of regions of calcification and normal tissue in the media of the arterial vessel wall. Biochem Biophys Res Commun 289:485-490

23. Carlson CS, Tulli HM, Jayo MJ et al (1993) Immunolocalization of noncollagenous bone matrix proteins in lumbar vertebrae from intact and surgically menopausal cynomolgus monkeys. J Bone Miner Res 8:71-81

24. Hirakawa K, Hirota S, Ikeda T et al (1994) Localization of the mRNA for bone matrix proteins during fracture healing as determined by in situ hybridization. J Bone Miner Res 9:1551-1557
25. Luo G, D’Souza R, Houge D et al (1995) The matrix Gla protein is a marker of the chondrogenesis cell lineage during mouse development. J Bone Miner Res 10:325-334

26. Lawton DM, Andrew JG, Marsh DR et al (1999) Expression of the gene encoding the matrix Gla protein by mature osteoblasts in human fracture non-unions. J Clin Pathol: Mol Pathol 52:9296

27. Bianco P, Bonucci E (1991) Endosteal surfaces of hyperparathyroidism: an enzyme cytochemical study on low-temperatureprocessed, glicol-methacrylate-embedded bone biopsies. Virchows Archiv A Pathol Anat 419:425-431

28. Dickson IR, Poole AR, Veis A (1975) Localization of plasma $\alpha_{2}$ HS-glycoprotein in mineralizing human bone. Nature $256: 430$ 432

29. Ohnishi T, Arakaki N, Nakamura O et al (1991) Purification, characterization, and studies on biosynthesis of a $59-\mathrm{kDa}$ bone sialic acid-containing protein (BSP) from rat mandible using a monoclonal antibody. J Biol Chem 266:14636-14645

30. Zweras M, Liu D, Partridge EA et al (2002) $\alpha_{2}$-HS glycoprotein/ fetuin, a transforming growth factor- $\beta /$ bone morphogenetic protein antagonist, regulates postnatal bone growth and remodeling. J Biol Chem 277:19991-19997

31. Triffitt JT, Gebauer U, Ashton BA et al (1976) Origin of plasma $\alpha_{2}$ HS-glycoprotein and its accumulation in bone. Nature 262:226-227

32. Yang F, Schwartz Z, Swain LD et al (1991) $\alpha_{2}$ HS-glycoprotein: expression in chondrocytes and augmentation of alkaline phosphatase and phospholipase $\mathrm{A}_{2}$ activity. Bone 12:7-15

33. Schinke T, Amendt C, Trindl A et al (1996) The serum protein $\alpha_{2^{-}}$ HS glycoprotein/fetuin inhibits apatite formation in vitro and in mineralizing calvaria cells. J Biol Chem 271:20789-20796

34. Ketteler M, Wanner C, Metzger T et al (2003) Deficiencies of calcium-regulatory proteins in dialysis patients: a novel concept of cardiovascular calcification in uremia. Kidney Int 63(suppl. 84): S84-S87

35. Kazama JJ, Gejyo F, Ei I (2005) The immunohistochemical localization of $\alpha_{2}$-Heremans-Schmid glycoprotein/fetuin-A (AHSG). Nephrol Dial Transplant 20:851-852

36. Chen NX, O'Neill KD, Chen X et al (2007) Fetuin-A uptake in bovine vascular smooth muscle cells (BVSMC) is calcium dependent and mediated by annexins. Am J Physiol Renal Physiol 292:F599-F606

37. Xie J, Baumann MJ, McCabe LR (2005) Adsorption of serum fetuin to hydroxylapatite does not contribute to osteoblast phenotype modifications. J Biomed Mater Res 73A:39-47

38. Ohnishi T, Nakamura O, Ozawa M et al (1993) Molecular cloning and sequence analysis of cDNA for a $59 \mathrm{kD}$ bone sialoprotein of the rat: demonstration that it is a counterpart of human $\alpha_{2}$-HS glycoprotein and bovine fetuin. J Bone Miner Res 8:367-377

39. Colclasure GC, Lloid WS, Lamkin M et al (1988) Human serum $\alpha_{2}$ HS-glycoprotein modulates in vitro bone resorption. J Clin Endocrinol Metab 66:187-192

40. Nakamura O, Kazi JA, Ohnishi T et al (1999) Effect of rat fetuin on stimulation of bone resorption in the presence of parathyroid hormone. Biosci Biotechnol Biochem 63:1383-1391 